\title{
O IMAGINÁRIO COLETIVO DE ESTUDANTES DE EDUCAÇÃO FÍSICA SOBRE PESSOAS COM DEFICIÊNCIA
}

\author{
Renata Costa de Toledo Russo \\ Thais Helena Andrade Machado Couto \\ Tânia Maria José Aiello Vaisberg \\ Pontifícia Universidade Católica de Campinas, Campinas, Brasil
}

\begin{abstract}
RESUMO: O presente trabalho objetiva o estudo do imaginário coletivo de estudantes de Educação Física sobre pessoas com deficiência. Articula-se, metodologicamente, em torno do uso do Procedimento de Desenhos-Estórias com Tema na abordagem coletiva de uma classe composta de trinta alunos. O material obtido foi psicanaliticamente analisado à luz da Teoria dos Campos. Constatamos que as concepções dos alunos sobre deficiência emergem a partir de dois campos psicológicos não-conscientes: "deficiência como sofrimento humano" e "deficiência como problema técnico". A nosso ver, o primeiro campo corresponde à possibilidade de assumir posturas sensíveis e cuidadosas diante da questão da deficiência, ao passo que o segundo expressa a ação de estratégias defensivas que visam a negar a importância de dimensões afetivo-emocionais ligadas ao sofrimento, tornando a pessoa com deficiência objeto de ações essencialmente técnicas.
\end{abstract}

PALAVRAS-CHAVE: deficiência; formação em educação física; imaginário coletivo; procedimento desenhoestória com tema.

\section{THE COLLECTIVE IMAGINARY OF PHYSICAL EDUCATION STUDENTS ABOUT DISABLED PEOPLE}

\begin{abstract}
The present work investigates the collective imaginary of Physical Education students about disabled people. It articulates methodologically on the use of the Thematic Drawing-and Story Telling Procedure to a collective approach of a class of thirty students. The obtained material was analyzed from a psychoanalytical perspective in light of the Theory of Fields. We verified that the conceptions of the students about disabilities arise from two non-conscious psychological fields: 'disability as human suffering' and 'disability as a technical problem'. In our view, the first field relates to the possibility of assuming sensitive and caring approaches when facing the disability issue, while the latter expresses the action of defensive strategies to deny the importance of the affective-emotional dimensions related to the suffering, turning the disabled person into an object of essentially technical actions.
\end{abstract}

KEYWORDS: disability; formation in physical education; collective imaginary; thematic drawing-and-story procedure.

\section{Introdução}

Este estudo tem como objetivo investigar psicanaliticamente o imaginário de estudantes de Educação Física sobre a deficiência, tendo em vista produzir conhecimentos que permitam aprimorar a formação profissional especialmente em relação ao aumento da sensibilidade que deve ser agregada, harmoniosamente, à aquisição de conhecimentos específicos.

Utilizamos o termo imaginário coletivo para designar conjuntos de manifestações imaginativas, vale dizer, de condutas que ocorrem na área mental de expressão, em âmbitos grupais. Adotamos, portanto, uma visão segundo a qual a conduta deve ser entendida como conjunto formado por "todas as manifestações do ser humano, quaisquer que sejam suas características de apresentação" (Bleger, 1984, p. 25)

Quando concebemos os imaginários coletivos como condutas, podemos realizar pesquisas que adotam como desenho básico a identificação das produções e a busca de pressupostos ideativo-emocionais subjacentes aos quais denominamos campos (Herrmann, 2001), que constituem o solo psíquico-existencial a partir do qual emerge toda e qualquer manifestação de conduta ${ }^{1}$.

Inicialmente concebido para investigar a dinâmica psíquica do paciente neurótico, individualmente atendido pelo psicanalista, o método psicanalítico veio a revelar, posteriormente, uma vocação mais ampla, que 
permitia a abordagem de toda e qualquer manifestação humana. Esse fato foi logo comprovado pelos estudos freudianos dedicados aos fenômenos sociais e culturais, que ficaram conhecidos como psicanálise aplicada. Entretanto, a versatilidade e a abrangência do método psicanalítico só vieram a ser demonstradas de modo rigoroso mais recentemente, no contexto da Teoria dos Campos (Herrmann, 2001). Assim, elementos constitutivos do método podem estar presentes e atuantes tanto quando se realizam entrevistas clínicas individuais como quando se abordam manifestações humanas nos mais variados contextos. Portanto, a teoria psicanalítica pode ser aplicada ao estudo de fenômenos sociais, de obras de arte, de acontecimentos históricos, enfim, de qualquer conduta, seja ela individual ou coletiva.

O método psicanalítico visa ao conhecimento dos determinantes afetivo-emocionais inconscientes das condutas manifestas. Para tanto, segue paradigmaticamente os passos adotados por Freud no dispositivo clínico de atendimento ao neurótico. Então, assim como na sessão psicanalítica se conjuga uma atitude fenomenológica, denominada "atenção flutuante", com o convite ao paciente para que se comunique tão livremente quanto possível, vale dizer, que "associe livremente", busca-se, em toda e qualquer pesquisa psicanalítica, configurar situações que permitam a instauração do campo psicanalítico fora do dispositivo clínico padrão. Em outros termos, podemos afirmar que se trata de estabelecer a possibilidade de comunicação dialógica entre pesquisador e participantes. $\mathrm{O}$ pesquisador trata de assumir uma postura de máxima abertura à expressão subjetiva dos participantes, enquanto estes são convidados a se colocarem da forma mais livre possível, o que pode ser facilitado pelo uso de procedimentos mediadores também conhecidos como "apresentativo-expressivos" (Aiello-Vaisberg, Correa, \& Ambrósio, 2000).

Desse modo, instauramos um campo dialógico entre pesquisadoras e participantes, no caso estudantes de Educação Física, tendo em vista conhecer tanto um tipo de conduta, ou seja, aquilo que imaginam sobre as pessoas com deficiências, como o campo psicológico não-consciente a partir do qual emergem.

\section{O Trilhar Metodológico}

Pesquisamos o imaginário de universitários de Educação Física sobre pessoas com deficiência utilizando o Desenho-Estória com Tema como um recurso facilitador dialógico.

O Procedimento de Desenhos-Estórias com Tema foi desenvolvido por Aiello-Vaisberg (1999) a partir de procedimento diagnóstico criado na Universidade de São Paulo por Walter Trinca, em 1976. É um procedimento de uso fácil, cujo rigor e potencialidade heurística têm sido comprovados, adaptando-se facilmente à pesquisa de diferentes objetos sociais em grupos de sujeitos com características variadas (Aiello-Vaisberg, 1999).

Esse recurso é de fácil utilização, válido para pessoas de qualquer faixa etária, em diferentes condições psicopatológicas e vivenciais, o que lhe confere grande versatilidade. Como estratégia de investigação clínica, que tem por base os desenhos livres e a invenção de histórias, consiste na solicitação de um desenho especificado em termos temáticos e na escrita de uma história sobre a figura desenhada. O recurso apresentado também traz aos sujeitos pesquisados e ao pesquisador uma situação favorável de expressão emocional. Em um segundo momento, os desenhos e as histórias são lidos e analisados num contexto também grupal de pesquisadores, no qual o foco é a captação do imaginário coletivo dos sujeitos pesquisados sobre o tema em questão.

No presente caso, solicitamos aos estudantes que desenhassem e escrevessem uma história sobre o tema "uma criança com problema", para analisar a visão desses universitários em relação às deficiências.

Sendo assim, a pesquisa realizada com os alunos da disciplina de Educação Física Adaptada do curso de Educação Física teve seu espaço no contexto do enquadre transicional de aprendizagem, no qual levamos em conta que a formação de educador dessa área requer mais do que simplesmente a transmissão de conhecimentos. Acreditamos que o conhecimento técnico é tão importante quanto captar o imaginário coletivo que rodeia todo o campo do saber específico e que essa modalidade de pesquisa clínica pressupõe uma intervenção, na medida em que se configura como um fenômeno intersubjetivo.

Tanto as produções gráficas como as produções verbais são mensagens por meio das quais o sujeito responde às solicitações do pesquisador. O objetivo de utilizar esse procedimento é o de estabelecer uma comunicação, um contato com o grupo pesquisado, deixando claro aos alunos que o interesse é a pesquisa do imaginário coletivo sobre o tema. As produções elaboradas com base no Procedimento "Desenhos-Estórias com Tema" foram analisadas seguindo os pressupostos da 'Teoria dos Campos' (Herrmann, 1984). Segundo esse autor, essa teoria é um veículo de comunicação conceitual que permite um manejo metodológico, propiciando a emergência de novos significados.

Resolvemos enunciar a instrução para os alunos, sujeitos desta pesquisa, dizendo para que desenhassem uma "criança com problema", e não uma "criança com deficiência", porque o tema da deficiência já estava implícito na disciplina ministrada, que trata exatamente da questão da adaptação da Educação Física para pessoas com deficiência. Esse fato, por si só, já apontava para os alunos que o tema da deficiência estava em pauta. 
Para identificar as concepções dos sujeitos envolvidos na pesquisa sobre 'uma criança com problema' pelos sujeitos envolvidos na pesquisa, procedemos à análise do material em duas etapas. Inicialmente, fizemos uma leitura livre, buscando identificar as concepções presentes no imaginário coletivo dos alunos colaboradores da pesquisa. Baseadas em autores que estudaram imaginários coletivos sobre dificuldades humanas (Borges, 1998; Martins, 2007), sabíamos que as concepções se organizariam, provavelmente, em torno de quatro dimensões: definição do problema, causalidade, consequências e solução. Certamente a complexidade da conduta admitiria a escolha de outras dimensões, mas optamos por fixar estas porque, tendo sido utilizadas em pesquisas anteriores, revelam tanto estar dotadas de certo poder heurístico, como permitem que os achados atuais sejam futuramente comparados com aqueles oriundos de investigações que focalizam outros grupos que também são vítimas de exclusão social $^{2}$. Desse modo, buscamos identificar as produções imaginárias ao longo desses quatro eixos. Numa segunda etapa, já bastante familiarizadas com os desenhos e as histórias desses alunos, realizamos a análise do material, visando a captar os campos psicológicos não-conscientes, com base na Teoria dos Campos de Herrmann (1984). Deixamo-nos guiar por suas recomendações ou "palavras de ordem": deixar que surja; tomar em consideração e completar a configuração de sentido. A primeira recomendação - "deixar que surja" - corresponde ao deixar-se impressionar emocional e intelectualmente pelo material; o segundo passo é "tomar em consideração" aquilo que se destacou, permitindo o surgimento de associações livres de ideias e a emergência de emoções; em seguida chegaremos a "completar a configuração de sentidos", vale dizer, a captar as regras afetivo-emocionais segundo as quais os campos estão estruturados.

\section{Identificando as Concepções do Imaginário}

Em suas produções imaginárias, surgiram definições da criança com problema como aquela que apresenta deficiências, predominantemente físicas. Aparecem, em menor número, a deficiência mental e a deficiência visual. Por outro lado, outras condições, como pobreza, orfandade e vitimização por maus tratos, são também lembradas para definir a criança com problema.

Os acidentes automobilísticos, de modo geral, e os atropelamentos em particular, são invocados como causas mais frequentes da deficiência, ao lado da atribuição do problema a causas congênitas.

Encontramos, como consequências mais enfatizadas, a dificuldade de acesso, o preconceito e a exclusão. São também referidas, com menor frequência, a não-aceitação da deficiência pelos próprios deficientes e a falta de preparo dos profissionais da área da educação.

Finalizando a identificação das concepções sobre deficiências, cabe analisar as possíveis soluções dadas pelos alunos. Na maioria das histórias, constatamos que os alunos não apresentam soluções para o problema, ainda que alguns sugiram melhores acessos e a superação pela prática do esporte.

\section{Dialogando com os Campos Psicológicos Não-Conscientes}

Uma vez identificadas as concepções imaginárias, procedemos à análise psicanalítica dos desenhosestórias à luz da Teoria dos Campos, levando em conta que a descoberta dos campos não-conscientes pode não ser determinada pela quantidade de vezes em que um tema aparece, mas pela intensidade da expressão ou da palavra (Martins, 2007). Quando delineados, os campos fornecem a compreensão do fenômeno estudado, com base nas concepções elaboradas pelos indivíduos. Sua importância reside no fato de criarem as condições vivenciais assumidas pelos indivíduos.

Por meio da leitura e da releitura dos desenhosestórias e da identificação das concepções do imaginário dos estudantes pesquisados, foram encontrados dois campos psicológicos, que denominaremos "deficiência como sofrimento humano" e "deficiência como problema técnico".

O campo da "deficiência como sofrimento humano" subjaz às produções que expressam tristeza, rejeição e desespero. Nestas, a deficiência se configura como condição essencialmente associada à angústia, que a nosso ver corresponde à possibilidade de assumir posturas sensíveis e cuidadosas diante da questão da deficiência (estória 1 e 2).

Convidamos o leitor a nos acompanhar em duas dessas estórias ${ }^{3}$.

Esse é Pedro... ele tem 7 anos. Situações da sua infância causaram-lhe traumas, o mais perigoso é a ausência de amar... Pedro não sabe amar. Ele teve complicações quando bebê causando-lhe paralisia numa de suas pernas. Por ter que se apoiar numa muleta ele se sente diferente das outras crianças. Tornou-se uma criança fria e que não gosta de construir relações com as pessoas, se fecha tornando-se assim uma criança sem brilho. Mas aos poucos a vida vai mostrar-lhe que ter problemas é negar a deficiência. 


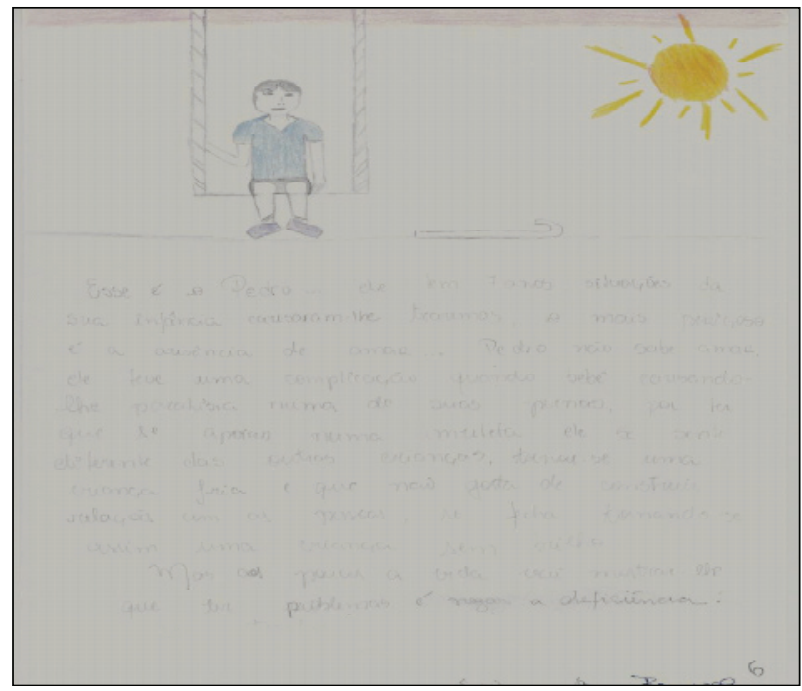

Malué uma criança de 7 anos, que logo que nasceu detectaram uma deficiência em seus membros inferiores e desde então, a família desesperada começou a procurar os mais variados tipos de tratamentos. Hoje Malu só consegue andar com o auxílio de botas ortopédicas e andador. Eagora começou a enfrentar dificuldades impostas pela sociedade, o preconceito. Na escola, todos sentem pena ao invés de tratá-la normalmente, além da dificuldade de se locomover em lugares não adaptados.

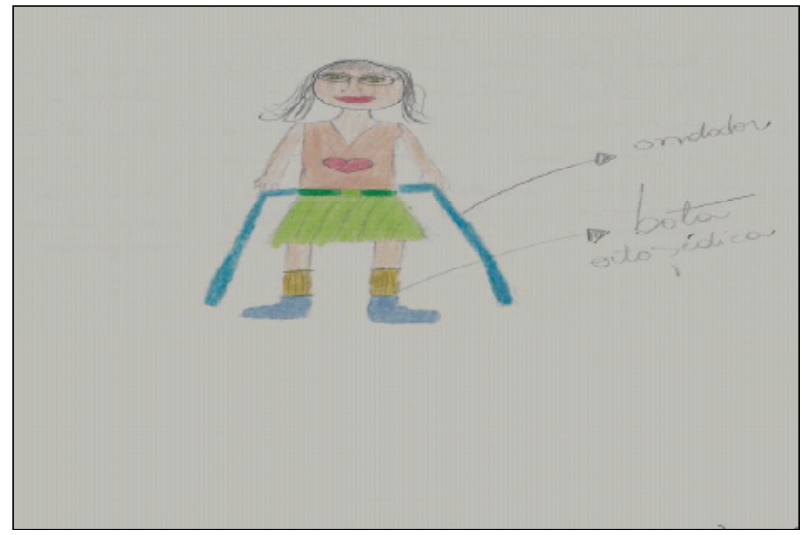

O segundo campo, que denominamos de "deficiência como problema técnico", mostra nas produções dos sujeitos pesquisados a preocupação como a resolução de problemas técnicos, fundamentalmente ligados ao espaço físico associada a uma visão defensiva que visa a negar a importância afetivo-emocional ligada ao sofrimento, tornando a pessoa com deficiência objeto de ações essencialmente técnicas.

Os desenhos-estórias que se inseriram nesse campo foram aqueles com deficiência predominantemente física, entrando em questão o estereótipo do corpo deficiente, ou seja, uma diferença visível e inaceitável. O material analisado aponta para o temor da diferença. No caso, essa diferença é temível porque revela a fragilidade do corpo e o fato de estarmos sujeitos a nos tornar vítimas da deficiência. O uso de estereótipos protege e ao mesmo tempo aprisiona em uma forma restrita de apreensão do mundo e de compreensão do outro, pensando no próximo como um outro diferente. Quando as diferenças são consideradas numa perspectiva estereotipada, focalizam-se somente as manifestações externas, deixando de valorizar e entender as pessoas que produzem tais manifestações.

Podemos citar as histórias seguintes como exemplos desse campo:

Guilherme é um cadeirante. Ele estuda em uma escola que se diz inclusiva. Em todas as aulas de Educação Física que acontecem em sua escola, ele fica do lado de cima observando a aula, porque a escola não possue [sic] nenhuma rampa que dê acesso à quadra. Em todas as aulas ele fica implorando para que alguém o leve até a quadra, mas infelismente [sic] Guilherme continua observando as aulas de longe, até que alguém se conscientize e faça uma transformação no cotidiano dessa pessoa especial.

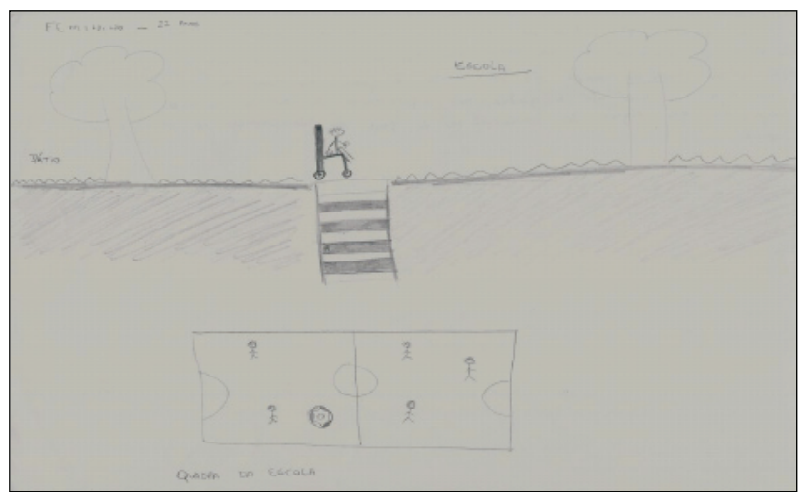

Pedro levava uma vida normal. Tinha todos seus membros do corpo em funcionamento. Devido a um acidente, perdeu metade de sua perna esquerda. Graças a uma tecnologia desenvolvida que temos atualmente, ele usa uma prótese no lugar da parte perdida da perna. Apesar de ter essa aparente limitação, ele teve coragem para provar a si mesmo que isso não seria o motivo para ele largar mão de seus gostos. Sempre acostumado a praticar esportes, ele teve força para recomeçar uma nova fase de sua vida. Com um olhar mais maduro de tudo que nos acontece na vida e como reagimos a isso. 


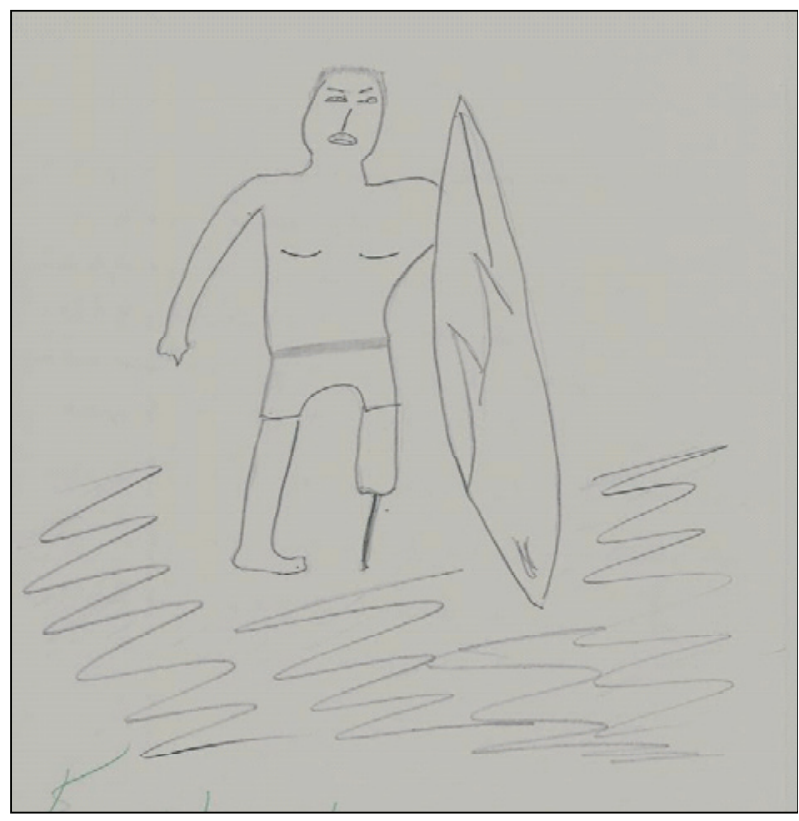

A nosso ver, o modo como surgem essas soluções, que operam num registro eminentemente pragmático, exige reflexão. Sem que faça sentido negar a importância de soluções concretas, que facilitem a acessibilidade e a adaptação, entendemos que é importante sinalizar um movimento de produção de sentido, mais ou menos sutil, presente nessas histórias, que insinua que próteses, aparatos, rampas e outros artefatos tecnológicos resolveriam "toda" a questão da deficiência. Podemos pensar, psicanaliticamente, que estamos diante de tentativas de negação de que a condição de pessoa com deficiência ocasiona mais do que transtornos de ordem prática e concreta, na medida em que gera repercussões afetivoemocionais e psicossociais importantes.

\section{Considerações Finais}

Consideramos que os resultados desta pesquisa são significativos uma vez que revelam a existência de duas tendências importantes no mundo imaginário dos estudantes de Educação Física: uma que consiste na percepção sensível do sofrimento humano intrinsecamente relacionado à questão da deficiência, e outra, que corresponde à redução dessa problemática a um registro meramente utilitário, pragmático e concreto. Cabe, portanto, perguntar se uma ou outra dessas tendências, que cada um dos campos encontrados indicou, facilita ou dificulta a adoção de práticas inclusivas e solidárias diante de pessoas com deficiências.

À primeira vista, poder-se-ia cogitar que a percepção de uma dimensão inerentemente angustiante na vivência da deficiência poderia favorecer atitudes de tipo inclusivo, na medida em que apontam para a presença de uma certa sensibilidade. Temos a impres- são de que essa ideia é verdadeira, mas não podemos deixar de considerar que pessoas sensíveis podem não ter condições emocionais de enfrentamento de situações difíceis. Assim, não há como ignorar que muitos alunos, entre aqueles capazes de perceber a ligação entre sofrimento e deficiência, podem vir a evitar situações profissionais nas quais poderiam ser agentes facilitadores da inclusão. Por outro lado, pode ser que muitos daqueles que se encaminham precipitadamente na busca de soluções pragmáticas comportem-se de modo menos sensível no início, mas estejam profundamente motivados a ajudar. Assim, o mais correto, a nosso ver, é reconhecer a complexidade do desafio que se coloca para o professor que busca uma formação que articule dimensões técnicas e éticas.

Correspondendo ao que tradicionalmente se espera da instituição escolar, a dimensão técnica pode ser satisfatoriamente suprida, no contexto formativo, por meio da transmissão cognitiva de conhecimentos e informações. Entretanto, no que tange às dimensões ética e afetiva, a situação é mais complexa, uma vez que não compete à escola a responsabilidade pelo processo de amadurecimento emocional dos indivíduos, ainda que em muito possa contribuir. De todo o modo, será bastante importante reconhecer que as necessidades de alunos mais ou menos sensibilizados, mais ou menos defendidos emocionalmente, podem ser bastante diversas, mesmo que haja uma convergência pela busca de posicionamentos ético-inclusivos.

Finalmente, vale lembrar que a psicanálise contemporânea reconhece que a capacidade de agir eticamente parece depender menos de uma escolha livre e racional do que do amadurecimento emocional atingido ao longo do processo do desenvolvimento pessoal (AielloVaisberg, 2005). Assim, “ensinar" posturas inclusivas significa, precisamente, tentar contribuir no processo de crescimento pessoal que permite o respeito à alteridade. Não se trata, portanto, de combater a insensibilidade e o desrespeito à alteridade com discursos moralizantes e sim de cuidar para que experiências, diretas e preparatórias, com pessoas com deficiências, sejam vividas de forma suficientemente confortável, do ponto de vista emocional, de modo a não tornar necessário o uso de estratégias defensivas. Evitando que a questão da inclusão se torne emocionalmente ameaçadora, o professor tem a opção de trabalhar no sentido da configuração de um ambiente de aprendizagem que propicie aos alunos mais sensíveis a possibilidade de poderem viver essa forma de ser, sem evitar esse campo de trabalho, e de contribuir para que os menos sensíveis - ou mais defendidos - possam conjugar sua propensão pragmática com o cultivo de posturas humanas e éticas, capazes de entrar em contato com o sofrimento alheio. 


\section{Notas}

1 Para maiores informações sobre este tipo de pesquisa, aconselhamos a leitura de Aiello-Vaisberg (1999), Martins (2007), Barreto (2006), Ferreira (2004) e Micelli-Baptista (2003).

2 No momento, várias pesquisas sobre grupos vítimas de exclusão social estão sendo desenvolvidas pelos pesquisadores do Grupo Atenção Psicológica Clinica em Instituições: Prevenção e Intervenção, do qual participamos, utilizando as dimensões definição, causas, soluções e consequências no estudo de imaginários coletivos.

3 Será respeitada a forma gramatical dos textos que compõem o corpus analisado

\section{Referências Bibliográficas}

Aiello-Vaisberg, T. M. J. (1999). Encontro com a loucura: transicionalidade e ensino de psicopatologia. Tese de livredocência, Instituto de Psicologia, Universidade de São Paulo, São Paulo.

Aiello-Vaisberg, T. M. J. (2005). Os monstros, o método e o estabelecimento da capacidade ética. In T. M. J. Aiello-Vaisberg \& F. F. Ambrósio (Orgs.), Cadernos Ser e Fazer: reflexões éticas na clínica contemporânea (pp. 09-26). São Paulo: Instituto de Psicologia da Universidade de São Paulo.

Aiello-Vaisberg, T. M. J., Correa, Y. B., \& Ambrósio, F. F. (2000). Encontros brincantes: o uso de procedimentos apresentativosexpressivos na pesquisa e na clínica winnicottiana. In Anais do IX Encontro Latino-Americano sobre o Pensamento de D.W.Winnicott (pp. 331-341). Rio de Janeiro: Encontro Latino-Americano sobre o pensamento de D.W.Winnicott.

Barreto, M. A. (2006). Do vôo preciso: considerando o imaginário coletivo de adolescentes. Tese de Doutorado, Programa de Pós-Graduação em Psicologia, Pontifícia Universidade Católica de Campinas, Campinas.

Bleger, J. (1984). A psicologia da conduta. (E. de O. Diehl, Trad. $2^{\mathrm{a}}$ ed.). Porto Alegre: Artes Médicas.

Borges, T. W. (1998). O procedimento desenhos-estórias como modalidade de Intervenção nas consultas terapêuticas infantis. Tese de Doutorado, Psicologia Clínica, Universidade de São Paulo, São Paulo.

Ferreira, J. C. (2004). Encontrando a mulher: a psicanálise do self na abordagem de um singular plural. Dissertação de Mestrado, Psicologia Clínica, Universidade de São Paulo, São Paulo.
Herrmann, F. (1979). Andaimes do real ( $3^{\mathrm{a}}$ ed.). São Paulo: Casa do Psicólogo.

Herrmann, F. (1984). O que é psicanálise (6 $6^{\mathrm{a}}$ ed.). São Paulo: Brasiliense.

Herrmann, F. (2001). Introdução à teoria dos campos. São Paulo: Casa do Psicólogo.

Martins, P. C. R. (2007). O amante competente e outros campos do imaginário de universitários sobre as dificuldades sexuais masculinas. Tese de Doutorado, Programa de Pós Graduação em Psicologia, Pontifícia Universidade Católica de Campinas, Campinas.

Micelli-Baptista, A. (2003). A consulta psicoprofilática ao residente de medicina: a proposta de um enquadre diferenciado à luz da perspectiva winnicottiana. Dissertação de Mestrado, Universidade de São Paulo, São Paulo.

Trinca, W. (1997). Formas de investigação clínica em psicologia. São Paulo: Vetor.

Renata Costa de Toledo Russo é graduada em Educação Física, mestre e doutora pela PUC-Campinas. Docente da Pontifícia Universidade Católica de Campinas e da Escola Superior de Educação Física de Jundiaí. Email: russo@puc-campinas.edu.br

Thaís Helena Andrade Machado Couto é graduada em Psicologia e Fonoaudiologia e Mestre em Psicologia Clínica pela PUC de Campinas. E.mail: dttcouto@uol.com.br

Tania Maria José Aiello Vaisberg é Livre docente da USP. Professora do Programa Strictu senso da PUC-Campinas. Email: aiello.vaisberg@gmail.com

O imaginário coletivo de estudantes de educação física sobre pessoas com deficiência

Renata Costa de Toledo Russo, Thaís Helena Andrade Machado Couto e Tania Maria José Aiello Vaisberg

Recebido: $13 / 03 / 2008$

$1^{\text {a }}$ revisão: $20 / 10 / 2008$

Aceite final: 03/12/2008 